\title{
Las bibliotecas y las exposiciones virtuales: orientaciones para su diseño
}

\author{
José Luis Herrera Morillas
}

Universidad de Extremadura (España)

\section{Resumen}

Se localizan, recopilan y analizan cien exposiciones virtuales organizadas por bibliotecas dentro de sus actividades de extensión y difusión cultural. Se presenta el protocolo de análisis seguido, describiendo con detalle tres ejemplos señeros. Se comenta el significado y finalidad de estos recursos, algunas de sus características y ventajas, y se establecen una serie de orientaciones a modo de sugerencia para su diseño. Se concluye que las exposiciones virtuales son complementarias de las presenciales; es frecuente que ofrezcan solo una selección de los objetos; multiplican las posibilidades de difusión y conocimiento para atraer a un mayor número de público; el número de exposiciones virtuales organizadas por las bibliotecas es bastante notable; son muy variadas en función de la temática, volumen de obras expuestas o diseño del soporte; se aprecian diferencias en la calidad de unas y otras, existiendo desde las que reúnen en una sola página unas cuantas imágenes, con o sin textos complementarios, hasta las que albergan cientos de imágenes introducidas en un completo y original contexto virtual.

Palabras clave: Exposiciones virtuales. Bibliotecas.

\section{Abstract}

A hundred of virtual exhibitions organized by libraries within their activities of extension and cultural diffusion are located, compiled and analyzed. The protocol of analysis is presented, describing with detail three signified examples. The meaning and purpose of these resources and their characteristics and advantages are presented, and a set of suggestions for their design is discussed. It is concluded that virtual exhibitions are complementary of the real ones; frequently, they offer only a selection of the objects; they multiply the possibilities of advertising to attract a greater number of public; their number is notable. They are varied in thematic, number of exposed works, design, and quality, with a great range from those that reunite in a single page a few images, with or without complementary 
texts, to those that shelter hundreds of images introduced in a complete and original virtual context.

Keywords: Virtual exhibitions. Libraries.

\section{Introducción}

En el contexto de nuestra sociedad, donde cada vez se da más importancia a la recuperación y puesta en valor del patrimonio histórico, las exposiciones son una actividad en auge dentro de la difusión de todos los bienes culturales testimonio de la civilización humana. Este es el contexto general en el que nos parece que se deben ubicar las exposiciones temporales.

Ciñéndonos al ámbito bibliotecario, una de las actividades tradicionales incluidas en los servicios de extensión y difusión cultural han sido las exposiciones temporales, debido a que toda biblioteca, y especialmente la pública, tiene que diversificar y ampliar sus funciones tradicionales de conservación y difusión, abriéndose a la sociedad mediante el fomento de actividades culturales. Estas actividades se enmarcan en la denominada por unos extensión cultural, y por otros acción cultural, que se puede definir como "la realización de actividades culturales puntuales o permanentes, promovidas por la biblioteca o asumidas por ella, que tienen como marco las propias instalaciones bibliotecarias u otras instalaciones, y por objeto satisfacer las necesidades y deseos de información de sus clientes mediante servicios diferentes a los tradicionales servicios mínimos bibliotecarios" (García, 1996).

La difusión forma parte de la intermediación entre la biblioteca y la sociedad y debe entenderse como el conjunto de acciones encaminadas a dar a conocer la biblioteca y poner los medios y los instrumentos precisos para que sea apreciada, valorada y disfrutada por el mayor número de usuarios. Así, para Carbornell (2005) la biblioteca ha adaptado sus recursos a las necesidades de sus usuarios produciendo aquella información que considera necesaria; y uno de los productos que se han ido consolidando en los últimos años han sido las exposiciones virtuales.

Las bibliotecas llevan tiempo adaptándose a las nuevas posibilidades que permite el entorno digital. En este contexto, las exposiciones virtuales son una manifestación más de las extraordinarias mutaciones acaecidas en la sociedad de la información que tanto eco están teniendo en instituciones como los museos y las bibliotecas. Con las actuales tecnologías de la información y la comunicación, estos centros se han introducido en nuestros hogares y podemos visitarlos a cualquier hora del día.

Para Ramos (2002), la exposición temporal ha formado parte inseparable de la cultura occidental - a diferencia de otras culturas - tanto como los propios 
museos. Su arraigo y su papel social han sido tan importantes como los de aquellos. Pero, más antiguas, más versátiles y experimentales que las exposiciones permanentes, han influido decisivamente en todo tiempo sobre estos. Su ventaja -y su diferencia más sustancial respecto a los museos - consiste en su vinculación con el divertimento y lo festivo tanto como con el conocimiento, ganando así un espacio de exposición no sacralizado.

Las exposiciones temporales están vinculadas tanto por su contenido como por su misión con la difusión del patrimonio histórico-artístico entendido este como

todos aquellos bienes materiales e inmateriales sobre los que, como en un espejo, la población se contempla para reconocerse, donde busca la explicación del territorio donde está enraizada y en el que se sucedieron los pueblos que la precedieron; un espejo que la población ofrece a sus huéspedes para hacerse entender, en el respeto de su trabajo, de sus formas de comportamiento y de su intimidad (1).

En el nuevo espacio que posibilita Internet se han instalado también las exposiciones para conseguir así una mayor proyección social. Estas exposiciones virtuales las podemos considerar como una réplica de las presenciales pero en soporte electrónico. Como afirman Talens y Hernández (1997) - refiriéndose a los museos virtuales - , no reemplazarán nunca a las visitas físicas para ver los originales, pero cuando la distancia o las posibilidades económicas no permiten ir, siempre pueden ser una opción muy válida para un primer acercamiento. Podemos decir que las nuevas muestras del entorno digital quieren disponer la virtualización al servicio de la difusión del patrimonio.

El trabajo que presentamos lo hemos elaborado después de localizar y analizar más de cien exposiciones virtuales de bibliotecas de todo el mundo (2), difundidas a través de Internet. Hemos comprobado la gran diversidad temática de las mismas, los distintos recursos empleados en su diseño, etc. Esta experiencia nos ha permitido conocer las cualidades que deben reunir estas muestras para conseguir sus objetivos. Cualidades que exponemos y desarrollamos en este trabajo en forma de orientaciones con el objetivo de que puedan ser utilizadas como guía para su diseño y evaluación.

\section{Características y ventajas de las exposiciones virtuales}

Gran parte de las exposiciones virtuales diseñadas por las bibliotecas son complementarias de las presenciales, y también es frecuente que ofrezcan solamente una parte pequeña de lo que pueden encontrar los usuarios visitando la exposición real. Por tanto, las exposiciones concebidas de este modo nos parece que no pueden competir con las presenciales sino que cumplen un papel complementario. Las posibilidades didácticas de la web pueden potenciar el papel comunicativo e interactivo de las muestras. 
Estar presente en Internet multiplica las posibilidades de difusión y conocimiento para atraer a un mayor número de público, a la vez que supone una reducción notable de los costos de organización y mantenimiento y de desplazamiento para los interesados. La diferencia fundamental entre uno y otro tipo de exposiciones radica en el modo de presencia de los objetos.

Para un sector del público, algunos documentos y objetos culturales presentan un oscuro significado y necesitan ser explicados mediante un contexto pedagógico, es decir, necesitan ser presentados de una manera didáctica. El hipertexto y la realidad virtual son dos herramientas excelentes para crear contextos didácticos para nuestro patrimonio cultural (Carreras, 2001).

Por otra parte, las exposiciones diseñadas en la red pueden superar los límites espaciales de las presenciales, circunstancia que dificulta y limita la posibilidad de visitarlas.

Para Desantes (2002), las exposiciones diseñadas en la red ofrecen ventajas como las siguientes: superan las tradicionales paredes de los edificios generando la posibilidad de ser "visitadas" 24 horas durante 7 días a la semana; perduran en el espacio y en su forma; rentabilizan de una manera real el tiempo y los recursos técnicos, humanos y económicos que se emplean en su diseño y montaje en la web, pues las exposiciones pueden incluirse, cuando se considere necesario o sean suficientemente visitadas, en una página o archivo de exposiciones ya celebradas, y también se puede aprovechar el esfuerzo invertido en el diseño y en la elaboración de contenidos textuales y de imágenes mediante la edición de una publicación en CD.

\section{Orientaciones y sugerencias para el diseño de exposiciones virtuales}

El número de exposiciones virtuales organizadas por las bibliotecas es bastante notable. Son muy variadas en función de la temática, volumen de obras expuestas o diseño del soporte. Por consiguiente, se pueden apreciar diferencias en la calidad de unas y otras, existiendo desde las que reúnen en una sola página unas cuantas imágenes, con o sin textos complementarios, hasta las que albergan cientos de imágenes introducidas en un completo y original contexto virtual.

Una estructura frecuente es la siguiente:

- Portada, en la que se incluyen los datos que identifican la muestra y a veces también el índice.

- Catálogo de la obras expuestas, que consituye el núcleo central con los documentos expuestos: imágenes, referencias, descripciones... 
- Otros elementos: información introductoria, textos de presentación y/o complementarios, enlaces, índices, créditos...

A continuación señalamos algunas indicaciones que, a nuestro entender, deben reunir estos recursos para conseguir una mínima calidad.

Como en toda exposición, en las muestras virtuales el elemento esencial está formado por los objetos, que en este caso los percibimos a través de las imágenes; por lo tanto estas se deben cuidar especialmente.

Conviene elegir diseños de web que destaquen por su impacto visual, en los que el centro sean las imágenes de las piezas expuestas; por ello las exposiciones más abundantes son las dedicadas a documentos como fotografías antiguas, grabados, mapas, dibujos y carteles, cartularios e incunables con magníficas ilustraciones (Vela, 2001).

Las imágenes deben lograr la máxima fidelidad respecto al original; la calidad de la muestra dependerá de la selección y digitalización de las imágenes de los documentos que se van a introducir en la exposición.

Las características esenciales que deben reunir las imágenes digitalizadas son las siguientes. La resolución debe situarse en torno a 75 píxels y en el caso de incluir la opción de ampliación de las imágenes la resolución óptima es de 800 píxels. El tiempo de descarga de las imágenes no debe ser excesivo y nunca debe superar los 20 segundos. El formato más utilizado es el JPEG, idóneo para Internet, pues puede definir 16 millones de colores y es fácil de comprimir. Otros formatos alternativos son GIF, MPEG y PNG.

Muy apropiados para la finalidad de estos eventos son los efectos animados y de movimiento, así como la incorporación de recreaciones virtuales e interactivas de la instalación de la exposición presencial, que permiten de este modo una auténtica inmersión en la exposición.

Los textos son parte destacada. Hay que distinguir entre los que acompañan a las imágenes (los que incluyen las datos catalográficos o los textos explicativos), que se deben presentar mediante un combinación adecuada con las imágenes, y los textos que forman parte de apartados complementarios como los documentos didácticos - para facilitar la interpretación (dossiers pedagógicos, vocabularios, cronologías, juegos, etc.) - o los textos dirigidos a contextualizar y profundizar en un aspecto determinado. En ambos casos se debe evitar la extensión excesiva y cuidar que estén redactados por entendidos en la materia, pero con un vocabulario no demasiado técnico o erudito.

Otro aspecto importante en relación con el diseño y estructura global de estos recursos virtuales es que se debe huir de la simple reproducción correlativa de las imágenes y textos. Por el contrario -y para que estas manifestaciones respondan 
al nombre con el que se han dado a conocer (exposiciones virtuales) - deben plasmar y facilitar la sensación de recorrido que caracteriza a las exposiciones físicas, así como incluir - adaptados al medio digital - los elementos característicos de las exposiciones: empleo adecuado y medido, mediante una pensada jerarquización, de los distintos tipos de textos (títulos, títulos secundarios, comentarios de los objetos) combinados con otros medios interpretativos como gráficos, dibujos, etc.

En este sentido las nuevas tendencias implementadas para el diseño de exposiciones virtuales se caracterizan por estar diseñadas a modo de "ventana" que nos introduce en el interior de la exposición física y presencial mediante la incorporación de recursos como planos, panorámicas, fotos o vídeos del interior de la instalación; así como por incorporar la interactividad para acceder a la visualización de las reproducciones de los objetos expuestos.

Respecto a la temática es importante seleccionar un tema que esté dentro de los centros de interés de los posibles visitantes, pero también que sea oportuno en cuanto al momento de su realización, aprovechando un acontecimiento, una conmemoración o un centenario.

\section{Ejemplos señeros de exposiciones virtuales}

Como modelos de exposiciones virtuales se comentan los tres ejemplos siguientes:

\section{1. Émile Zola: Au Bonheur des Dames}

Esta muestra fue realizada por la Biblioteca Nacional de Francia como complemento de la exposición presencial celebrada del 18 de octubre de 2002 hasta el 13 de abril de 2003, y está disponible en http://expositions.bnf.fr/zola/ index.htm.

Se basa en los documentos preparatorios de la novela de Emilio Zola. Incluye unos 300 documentos que permiten descubrir aspectos como el París de Haussman, el auge de los grandes almacenes, el nacimiento del comercio moderno o las consecuencias sociales de los cambios económicos que se produjeron bajo el Segundo Imperio.

Se inicia con una portada (figura 1) que lleva el índice general. En él destaca, entre otros apartados, la sección "en imágenes", en la que alberga el grueso de la muestra, subdividida en apartados temáticos: "una nueva sociedad"; "nacimiento del comercio moderno"; "espacio de la villa, espacio de la novela" y "la novela de la modernidad". El inicio de cada apartado está diseñado mediante una página con juegos de imágenes de la época en movimiento. Es la entrada a varias "salas" que muestran imágenes de los documentos, acompañadas de breves comentarios, 


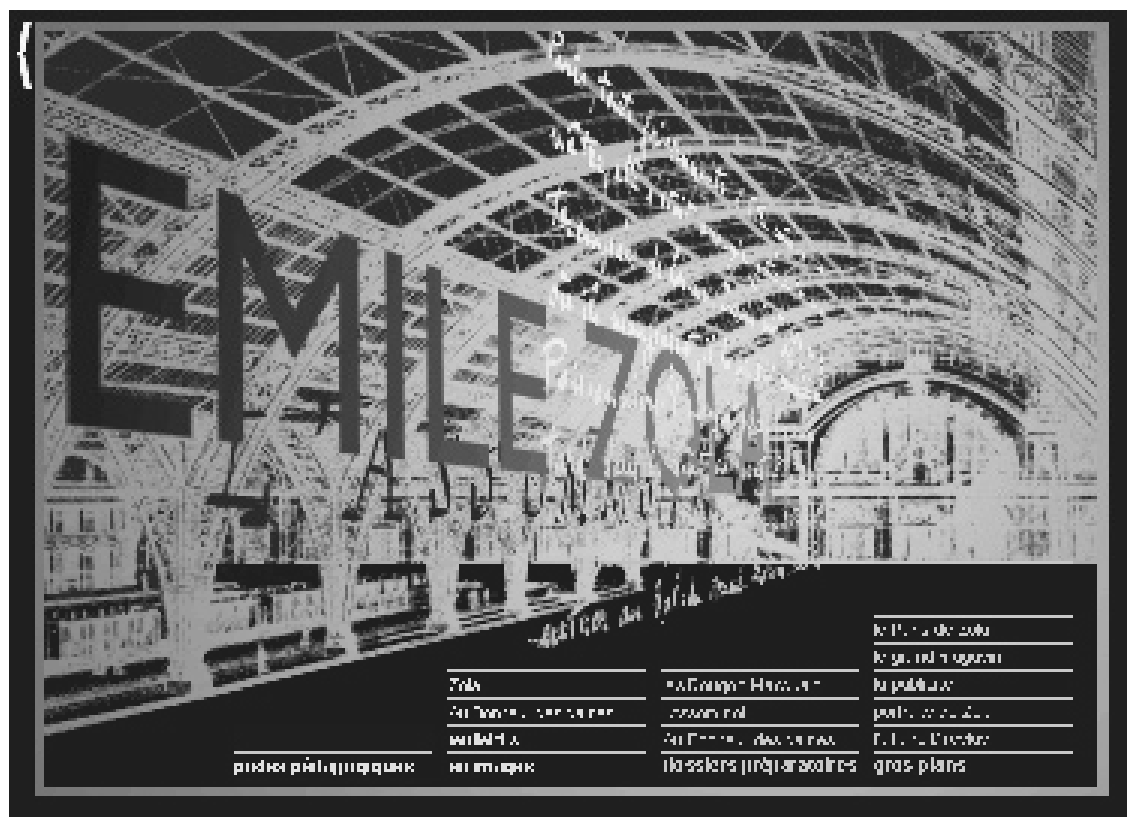

Figura 1. Página de presentación de la exposición Émile Zola: Au Bonheur des Dames

accediendo a cada una mediante una secuencia lineal. En todo momento están presentes los accesos al resto de los apartados para que el público pueda dirigirse al que prefiera.

Otras secciones en que se estructura la web de esta exposición virtual son "el dossier preparatorio" (con información textual y audiovisual sobre aspectos como personajes, decorados, etc.); "el París de Zola" (plano de París subdividido en zonas que incluye enlaces a grabados relacionados); "el gran almacén" (con grabados y láminas de esta temática); e "información" (datos prácticos para la visita de la exposición).

\subsection{India: Pioneering Photographers 1850-1900}

Incluida en la sección de exposiciones de la Biblioteca Británica, tiene por tema fotografías antiguas sobre la India conservadas en el Museo de la Commonwealth y del Imperio Británico de la India, organizada en colaboración con la Biblioteca Británica e inaugurada el 26 de septiembre de 2002. Está disponible en http://www.bl.uk/whatson/exhibitions/india2/overview.html.

En el siglo XIX la India estaba en la vanguardia del desarrollo fotográfico. La exposición incluye una amplia gama de estas imágenes, muchas de las cuales 


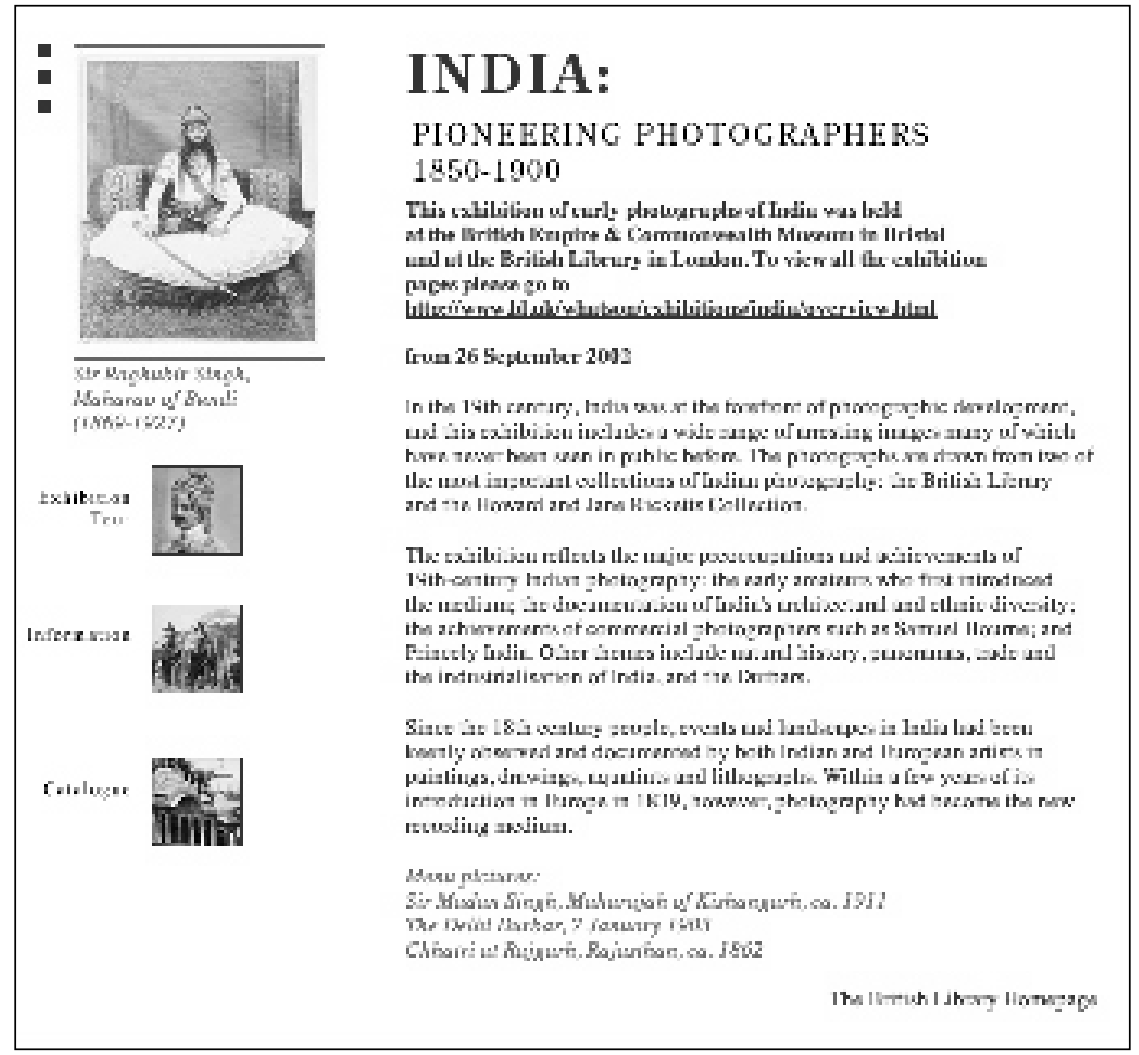

Figura 2: Página de la sección “Exhibition tour” de la exposición India: Pioneering Photographers 1850-1900

nunca han sido expuestas al público. Las fotografías forman parte de dos de las colecciones más importantes de fotografía india: los fondos de la Biblioteca Británica y la colección de Howard y Jane Ricketts.

La exposición refleja las obras de los primeros fotógrafos que introdujeron el medio; la diversidad arquitectónica y étnica de la India; los logros de fotógrafos comerciales tales como Samuel Bourne y Princely; la historia natural; el comercio o la industrialización de la India. A ella se accede a través de una página de presentación que está diseñada con una cabecera con el título y fecha de celebración; un texto de presentación; y el índice general, anunciador de los tres apartados en que se organiza la muestra: paseo por la exposición, información y catálogo. El primero permite realizar un recorrido secuencial por 21 fotografías; cada una se presenta en una página independiente (figura 2) que contiene la 
imagen (con posibilidad de ampliación) y un texto explicativo. El segundo reúne datos prácticos sobre la muestra y el tercero está dedicado al catálogo impreso.

\subsection{El Quijote: biografía de un libro}

Esta muestra - disponible en www.bne.es/esp/quijote/index.htm - está vinculada a la exposición presencial del mismo nombre celebrada del 12 abril al 2 de octubre de 2005 en la Biblioteca Nacional de España (figura 3). Su estructura incluye una página de inicio con el nombre y el logotipo de la exposición, que da paso a la exposición propiamente dicha, formada por otra página con un plano de la planta de la exposición y una panorámica del interior, que permite visiones desde distintos ángulos. Puntos y cámaras con efecto de parpadeo en el plano nos avisan de las opciones disponibles, que, una vez pulsadas, se presentan en la pantalla panorámica del interior de la instalación, donde, de nuevo, el efecto de parpadeo nos orienta hacia los objetos que podemos visualizar con detalle. Los fondos expuestos son de la citada Biblioteca: más de 30 libros, 14 grabados, 2 esculturas; también incluye imágenes de la sección multimedia. De cada obra se aporta una sola imagen y permite las opciones de impresión y ampliación. Los efectos animados y de movimiento están muy presentes. Como elementos textuales se incluyen las descripciones bibliográficas de los libros. Se alberga el plano de la exposición presencial y las visiones panorámicas del interior, que son los

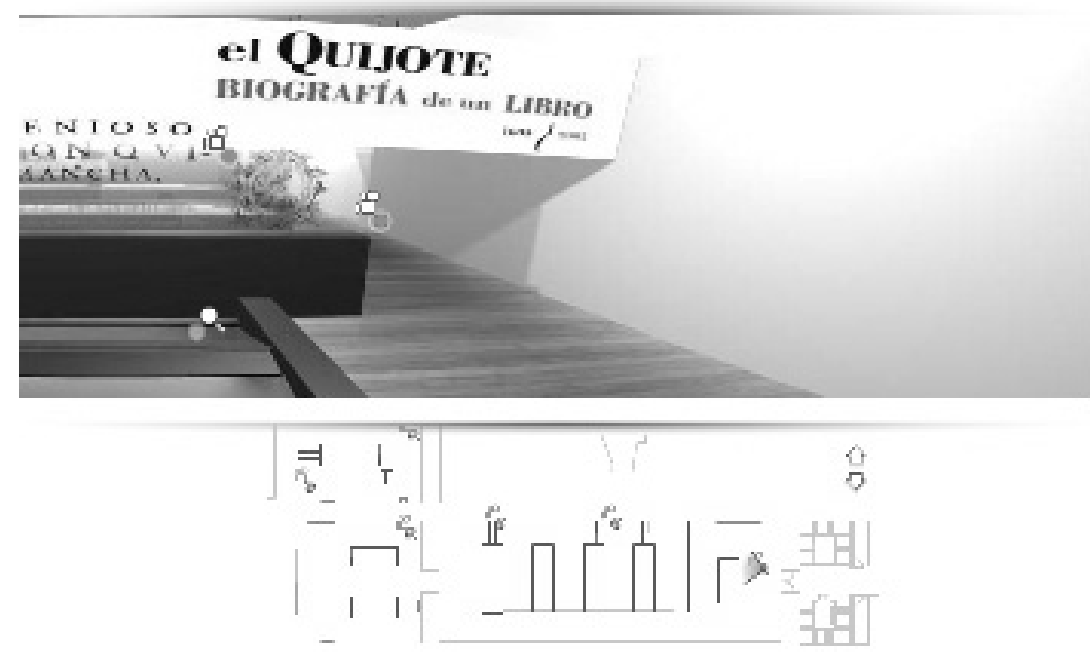

Figura 3: El Quijote: biografía de un libro

Scire. $11: 1$ (en.-jun. 2005) 113-122. ISSN 1135-3761. 
componentes en los que se basa el diseño de la exposición virtual, en el que se ha tenido muy en cuenta la interactividad.

\section{Notas}

(1) Citado en Necesidad de la belleza (notas sobre la difusión del patrimonio en la sociedad de la comunicación masiva). URL.: <http://www.iaph.junta-andalucia. es/Dossiers/dossier1art2.htmlc>. Consultado: 2002-02-17.

(2) En las siguientes direcciones se pueden encontrar una buena representación de las exposiciones analizadas: http://www.loc.gov/exhibits/, http://expositions.bnf.fr/, http://www.kb.nl/menu/expo_coll.html, http://www.nb.no/opplevelser.

\section{Referencias}

Bibliothèque Nationale de France. Expositions virtuelles. URL: <http://expositions.bnf. fr>. Consultado: 2003-10-05.

Carbonell, Marina (2005). Les exposicions virtuals a la Biblioteca d'Humanitats: una experiencia i un servei més que satisfactoris. // Item. 39 (2005) 39-46.

Desantes Fernández, Blanca (2002). Las exposiciones en archivos: las exposiciones virtuales. // Robot García, Luis A. (coord.). El libro, las bibliotecas y los archivos en España. Madrid: Sociedad Estatal España Nuevo Milenio, 2002, 319-337.

Carreras Monfort, César (2001). Virtual Exhibitions: Extending Museum Potencial. URL: $<$ http://www.cultivate-int.org/issue2/virtual/>. Consultado: 2001-07-03.

Exposities \& Collecties. URL: <http://www.kb.nl/menu/expo_coll.html>. Consultado: 2003-10-05.

García Rodríguez, Araceli (1996). Actividades culturales en la biblioteca. // Orera Orera, Luisa (ed.). Manual de Biblioteconomía. Madrid: Síntesis, 1996, 289-296.

Koninklijke Bibliotheek. Nasjonalbblioteket Opplevelser. URL: <http://www.nb.no/ opplevelser>. Consultado: 2003-10-05.

The Library of Congress. Exhibitions. URL: <http://www.loc.gov/exhibits/>. Consultado: 2003-10-05.

Necesidad de la belleza (notas sobre la difusión del patrimonio en la sociedad de la comunicación masiva). URL: <http://www.iaph.junta-andalucia.es/Dossiers/ dossier1art2.htmlc>. Consultado: 2002-02-17.

Ramos Lizana, Manuel (2002). El fenómeno social de las exposiciones temporales. URL: <http://www.iaph.junta-andalucia.es/Dossiers/art6dossieer9.htm>. Consultado: 2002-07-17.

Talens Oliag, S.; Hernández Orallo, J. (1997). Internet: Redes de Computadores y Sistemas de Información. Madrid: Paraninfo, 1997.

Vela, Susana (2001). La organización de exposiciones. // Archivos y cultura: manual de dinamización. Gijón: Ediciones Trea, 2001. 85-106. 